\title{
Species' traits as predictors of avoidance towards roads and traffic
}

\section{Article}

\section{Accepted Version}

Creative Commons: Attribution-Noncommercial-No Derivative Works 4.0

Duffett, D., D'Amico, M., Mulero-Pázmány, M. and GonzálezSuárez, M. (2020) Species' traits as predictors of avoidance towards roads and traffic. Ecological Indicators, 115. 106402. ISSN 1470-160X doi: https://doi.org/10.1016/j.ecolind.2020.106402 Available at https://centaur.reading.ac.uk/90004/

It is advisable to refer to the publisher's version if you intend to cite from the work. See Guidance on citing.

To link to this article DOI: http://dx.doi.org/10.1016/j.ecolind.2020.106402

Publisher: Elsevier

All outputs in CentAUR are protected by Intellectual Property Rights law, including copyright law. Copyright and IPR is retained by the creators or other copyright holders. Terms and conditions for use of this material are defined in the End User Agreement.

\section{www.reading.ac.uk/centaur}

\section{CentAUR}

Central Archive at the University of Reading 
Reading's research outputs online 
1 Title: Species' traits as predictors of avoidance towards roads and traffic

2

3 Authors: Daniela Duffett ${ }^{\mathrm{a}, \dagger}$, Marcello D’Amico ${ }^{\mathrm{b}, \mathrm{c}, \dagger}$, Margarita Mulero-Pázmány ${ }^{\mathrm{d}}$, Manuela

4 González-Suárez ${ }^{\mathrm{a}, *}$

5

6

\section{Affiliations:}

${ }^{a}$ Ecology and Evolutionary Biology, School of Biological Sciences, University of Reading, Reading, RG6 6AS, UK

b THEOECO, CIBIO-InBIO, University of Porto, Vairão, 4485-661, Portugal

${ }^{c}$ School of Agriculture, CEABN-InBIO, University of Lisbon, Lisbon, 1349-017, Portugal

${ }^{\mathrm{d}}$ School of Biological and Environmental Sciences. Liverpool John Moores University, UK

* Corresponding author: manuela.gonzalez@ reading.ac.uk

${ }^{\dagger}$ These authors contributed equally

\section{Declarations of interest: none.}

\section{Abstract}

Road-networks and their associated motorized traffic pose a threat to biodiversity and ecosystems, with different groups of species exhibiting different avoidance responses. The often species-specific nature of these behavioural responses to roads and traffic suggest that morphological, ecological, life-history and behavioural traits could be useful in explaining and predicting these responses. Trait-based predictive models have been used to assess extinction risk, land use impacts, and road mortality. Here we present the first, to our knowledge, test of their potential to address animal road avoidance. We studied the fleeing responses and spatial distribution in relation to roads of diverse ungulate species across three South African protected areas. Our results show that smaller, solitary species with nongrazing food habits are more likely to flee in response to presence of a vehicle. None of the tested traits showed a clear relationship based on biological hypotheses with initial distance to roads and tolerance distance to vehicles (used to describe behavioural avoidance towards roads and vehicles, respectively). However, we found significant effects that supported proposed methodological hypotheses. Our results show the potential to use traits as indicators of vehicle and traffic avoidance. Obtaining behavioural avoidance data in the field for many species and areas can be time consuming, but here we show it may be possible to use 
34 available trait data to generally predict species responses. This could be useful for initial 35 species risk assessments.

36

37 Keywords: African ungulates, ecotourism, flight response, road avoidance, road ecology, 38 traits-based model. 


\section{Introduction}

The rapid and global expansion of road infrastructures and associated motorized traffic pose a great threat to biodiversity and ecosystems worldwide (Laurance et al., 2014; Ibisch et al., 2016), even within protected areas (Garriga et al., 2012; Monz et al., 2016). Roads and traffic affect wildlife by causing mortality due to collisions with vehicles (Coelho et al., 2008; D’Amico et al., 2015; González-Suárez et al., 2018) and fragmenting and destroying habitat (Forman, 2000; Eigenbrod et al., 2008). The latter include direct loss due to road construction, as well as indirect losses via traffic emissions (e.g. noise, light, chemical pollution) deteriorating habitat quality within road-effect zones (Forman and Deblinger, 2000; Laurance et al., 2014). The combined action of increased mortality by roadkill and avoidance behaviours towards road-effect zones can produce barrier effects, which can lead to population fragmentation, genetic isolation and even local extinction (Grilo et al., 2012; CeiaHasse et al., 2018).

Distinct groups of species often exhibit different avoidance responses within road-effect zones, including: road avoidance (which includes road-surface avoidance and habitat-gap avoidance), traffic-emissions avoidance, and vehicle avoidance (Jaeger et al., 2005; D'Amico et al., 2016). Road-surface avoidance is common among small-sized species, such as rodents, that avoid the hostile conditions of the road surface (e.g. materials, temperature; McGregor et al., 2008; Brehme et al., 2013). Canopy birds and arboreal mammals usually exhibit habitatgap avoidance caused by both natural and artificial gaps in the vegetation (Laurance et al., 2004; Chen and Koprowski, 2016). Traffic-emissions avoidance is probably the most common behavioural response to roads and traffic, with different species responding to different types of emissions. For example, nocturnal mammals tend to avoid street lights (Francis et al., 2015), many songbirds avoid traffic-related noise (including experimental phantom roads; McClure et al., 2013) and some ungulates preferentially graze away from linear infrastructures due to road dust (Ndibalema et al., 2008). Finally, vehicle avoidance mostly affects species that approach roads but still react to oncoming vehicles, a reaction observed in several scavenger species (Rytwinski and Fahrig, 2012).

The species-specific nature of behavioural responses to roads and traffic suggests that some morphological, ecological, life-history and behavioural traits could be useful to explain and predict these responses. Although previous studies have postulated that species' traits should produce, in turn, species-specific variations in animal abundance related to roads and traffic (Fahrig and Rytwinski, 2009; Rytwinski and Fahrig, 2011, 2012, 2013; Francis, 2015), no previous research, to our knowledge, has directly investigated the relationship between 
species' traits and behavioural responses to roads and traffic, and the potential of applying trait-based model to assess avoidance responses to roads and traffic/vehicles. Past studies have considered how species' traits influence roadkill probability (Ford and Fahrig, 2007; Barthelmess and Brooks, 2010; Cook and Blumstein, 2013; D’Amico et al., 2015; Santos et $a l ., 2016)$, but only recently the full potential for using trait-based models in Road Ecology has started to be considered, and for now has only been explored for estimates of roadassociated mortality (González-Suárez et al., 2018).

Our study addresses this knowledge gap by exploring the value of diverse species' traits to understand ungulate behavioural responses to roads and traffic. We considered several species' traits reflecting different biological hypotheses (Table 1) based on the general assumption that roads and vehicles can be perceived as a danger, similar to predators, by ungulates (Frid and Dill, 2002; Lima et al., 2015). We hypothesize an effect of morphology on avoidance responses, because smaller species have been found to be more cautious towards potential predators than larger species (Berger and Cunningham, 1988). Research has shown that ungulates such as pronghorns Antilocapra americana in North America (Gavin and Komers, 2006) and Tibetan antelopes Pantholops hodgsonii in Asia (Lian et al., 2011) can respond to vehicles as if these were predators. Species with relatively larger brains have greater learning and cognitive capacity (Shultz and Dunbar, 2006), thus, we propose they may be able to realize that vehicles are not actual predators (within protected areas) and show no or limited avoidance responses. Foraging habits have been shown to affect anti-predatory responses; the spatial distribution of browsing ungulates, but not of grazing species, has been shown to change in response to predators (Valeix et al., 2009), thus, we predict browsing species will avoid roads and vehicles more often. Longevity may also be important because long-lived species have greater learning capacities (Street et al., 2017) and their longer lifespan can allow them to learn by experience that vehicles are not predators. The trade-off between investment in reproduction and survival (Promislow and Harvey, 1990) proposes that slow-breeding species will invest more in self-maintenance and thus, should be more cautious towards potential predators (or roads and vehicles) than fast-breeding species. Finally, solitary species have been shown to be more wary of potential predators than gregarious species (Hunter and Skinner, 1998), thus we predict solitary animals will show higher avoidance. As alternative hypotheses, we considered methodological effects, mostly associated to detectability, that could also result in association between species' traits and behavioural responses (all biological and methodological hypotheses are summarized in Table 1). 
To test these hypotheses, we analysed data from multiple ungulate species collected along the heterogeneous road-networks of three African protected areas (Fig. 1). We selected this system because African ungulates are relatively easy to detect from the road (MuleroPázmány et al., 2016; González-Suárez et al., 2017), and are important components of African ecosystems due to their roles as prey, ecosystem engineers and, in some cases,

111 keystone species (e.g., Waldram et al., 2008; Pringle et al., 2007; Coverdale et al., 2016).

112 Using this study system as a case study, we test the value of predictive trait-based models for 113 avoidance behaviours towards roads and traffic. This approach can contribute to identify 114 susceptible species and potentially generate risk assessments.

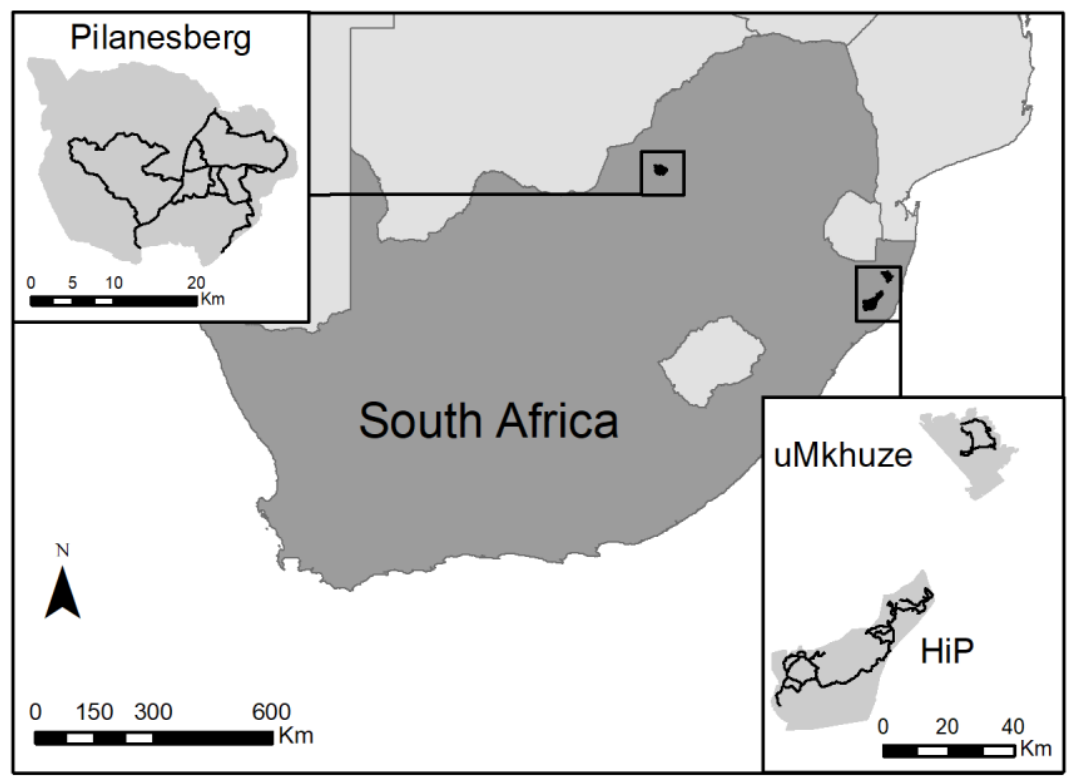

116 Figure 1. Map of the three studied protected areas in South Africa. Insets show the park boundaries and sampled transects.

\section{Methods}

\subsection{Study area}

Behavioural data were collected in three South African protected areas: HluhluweiMfolozi Park (from here on, HiP; $28.2198^{\circ} \mathrm{S}, 31.9519^{\circ} \mathrm{E}$ ), Pilanesberg National Park $\left(25.2449^{\circ} \mathrm{S}, 27.0891^{\circ} \mathrm{E}\right)$, and uMkhuze Game Reserve $\left(27.6519^{\circ} \mathrm{S}, 32.2435^{\circ}\right.$ E. Fig. 1$)$. All these protected areas allow regulated human activities based on wildlife-watching tourism and have road-networks that include paved and unpaved road surfaces and varying traffic volumes

126 (from virtually no vehicles to high-traffic intensity). The areas host diverse ungulate communities including abundant impala Aepyceros melampus, small steenbok Raphicerus campestris and large and iconic species such as African bush elephant Loxodonta africana and white rhinoceros Ceratotherium simum (Table 2 includes all observed species). 


\subsection{Data collection}

Data were collected on African ungulate species in October 2016 along 66 transects consisting of both unpaved and paved roads, totalling $722 \mathrm{~km}$ surveyed (HiP: 36 transects,

$134401 \mathrm{~km}$ of road sampled; Pilanesberg: 26 transects, $274 \mathrm{~km}$; uMkhuze: 4 transects, $47 \mathrm{~km}$;

135 Fig. 1). Each transect was sampled twice (except in uMkhuze where transects were surveyed once), driving in opposite directions and at different times of the day: once at either sunrise (06:00-07:00 h, local time) or sunset (17:00-18:00 h, local time) and another time at central hours of the day, to capture variability in daily activity patterns. Observations were gathered from a $4 \times 4$ vehicle driving at $<30 \mathrm{~km} / \mathrm{h}$.

For each transect, two observers searched for individuals of any ungulate species located <320 m from each side of the road (estimated range of detection; Mulero-Pázmány et al., 2016; González-Suárez et al., 2017), whilst a third observer noted the number of vehicles circulating in the opposite direction. The number of incoming vehicles over the duration of the transect sampling was used to estimate traffic intensity. When an individual was sighted, the vehicle was stopped in the closest possible location while remaining on the road. The position of the vehicle was recorded using a GPS (Garmin GSPMAP 62, KS, USA) and the side of the road where the individual was located noted. If more than one individual of the same species was sighted together, the one closest to the road was selected as the focal individual and the minimum group size was estimated (the group size is a minimum because some individuals could be out of sight). When possible, sex of the focal individual and group composition (mixed sex and presence of young) were recorded.

For each sighting we recorded the distance from the road to the focal individual using an Opticron Tracker 670 rangefinder and noted if the individual exhibited a flight response, escape motion in reaction to a stimulus possibly indicative of danger (Stankowich, 2008). We recorded two distances: 1) initial distance - minimum perpendicular distance from the road to the initial location of the focal individual, 2) tolerance distance - minimum perpendicular distance to the road at which the focal individual was stationary in the presence of a stopped vehicle (following Mulero-Pázmány et al., 2016). Both distances were measured directly when possible or using reference points if the individual had moved. Initial and tolerance distances were identical if the individual did not move between the time it was first observed and the time our vehicle stopped. Tolerance distance could not be estimated sometimes

162 because the focal individual did not stop moving while being observed or moved out of sight.

163 It is important to note that recorded tolerance distances may not correspond to the minimum 
164 at which individuals can tolerate vehicles or to the commonly used flight-initiation distance

165 FID (Frid and Dill, 2002). In these study areas it was not possible to leave the road to approach individuals until they fled as required to estimate FID.

Georeferenced locations were matched to habitat ecozones obtained from Park authorities. Original habitat types were reclassified into simplified categories for analyses (Supplementary materials, Table A1). Spatial analyses were done in ArcGIS 10.4 with Cape Zone $36 S$ Deprecated projection (EPSG: 22236). Trait data for all species observed during the field study were obtained from published sources (Table 1).

\subsection{Data analysis}

We used generalized linear mixed effects models (GLMM) to evaluate if traits predicted initial distance, tolerance distance and flight response. We fitted separate models for each of the trait groups we considered (Table 1). All models included control predictors related to each observation: road surface (unpaved or paved), traffic intensity, and standardized group size. When modelling flight responses, initial distance was also included as a predictor. Observed minimum group size was standardized within species to facilitate comparison. For each observation, we subtracted the mean observed for the species and divided by the standard deviation. Therefore, positive standardized group sizes represent groups larger than the average observed group size for that species.

To avoid confounding allometric effects of body mass when testing brain mass, longevity, sexual maturity age, gestation length, and litters per year we used standardized residuals from log-log phylogenetic least squares models in which each of these traits was predicted by body mass (all variables were $\log _{10}$ transformed). We used the function pgls from the caper package (Orme et al., 2013), using the updated mammalian supertree (Fritz et al., 2009) to describe phylogenetic relationships.

Finally, to account for confounding factors associated to particular habitats, transects and the non-independence of trait data from related species, all GLMMs included habitat ecozones, a nested effect of park, observation date, and transect ID, and a taxonomic correction with genus nested within family. Distances were first transformed $\left(\log _{10}[\mathrm{x}+1]\right)$ and then modelled using the function lmer in the package lme4 (Bates et al., 2015) with a Gaussian family. Flight response was modelled using the function glmer from the package lme4 using a binomial family (logit link). We evaluated predictor importance estimating 95\% confidence intervals using bootstrapped sampling (using the function confint.merMod, with 2000 simulations and method="boot" from the package lme4). We calculated Variance 
198 Inflation Factors (VIF) for all models to detect collinearity issues. All analyses were

199 completed in $\mathrm{R}$ version 3.3.2 (R Core Team, 2016).

All data and R scripts of completed analyses are available in the public repository

201 Figshare (https://doi.org/10.6084/m9.figshare.12117564.v1).

\section{Results}

204 We recorded 513 sightings representing 18 species of African ungulates (Table 2). Tolerance

205 distance was estimated for 448 of those sightings representing 17 species (no tolerance

206 distance estimates were available for black rhino Diceros bicornis). In $20.7 \%(\mathrm{~N}=106)$ of

207 those sightings we detected a flight response. Across all three parks we had a mean of 7.14

208 observations $/ 10 \mathrm{~km}(\mathrm{SD}=4.36)$ with more observations in unpaved roads (mean $\pm \mathrm{SE}=7.53$

$209 \pm 4.72$ observations $/ 10 \mathrm{~km})$ than in paved roads $(6.35 \pm 3.49)$. The overall mean traffic

210 intensity was 0.14 vehicles per minute $(\mathrm{SD}=0.18)$, with more traffic in paved $(0.26 \pm 0.24$

211 vehicles per minute) than in unpaved roads $(0.08 \pm 0.08)$. Traffic intensity varied by park,

212 with higher levels in Pilanesberg $(0.19 \pm 0.23)$ and HiP $(0.12 \pm 0.13)$ than in uMkhuze $(0.03 \pm$ $2130.04)$.
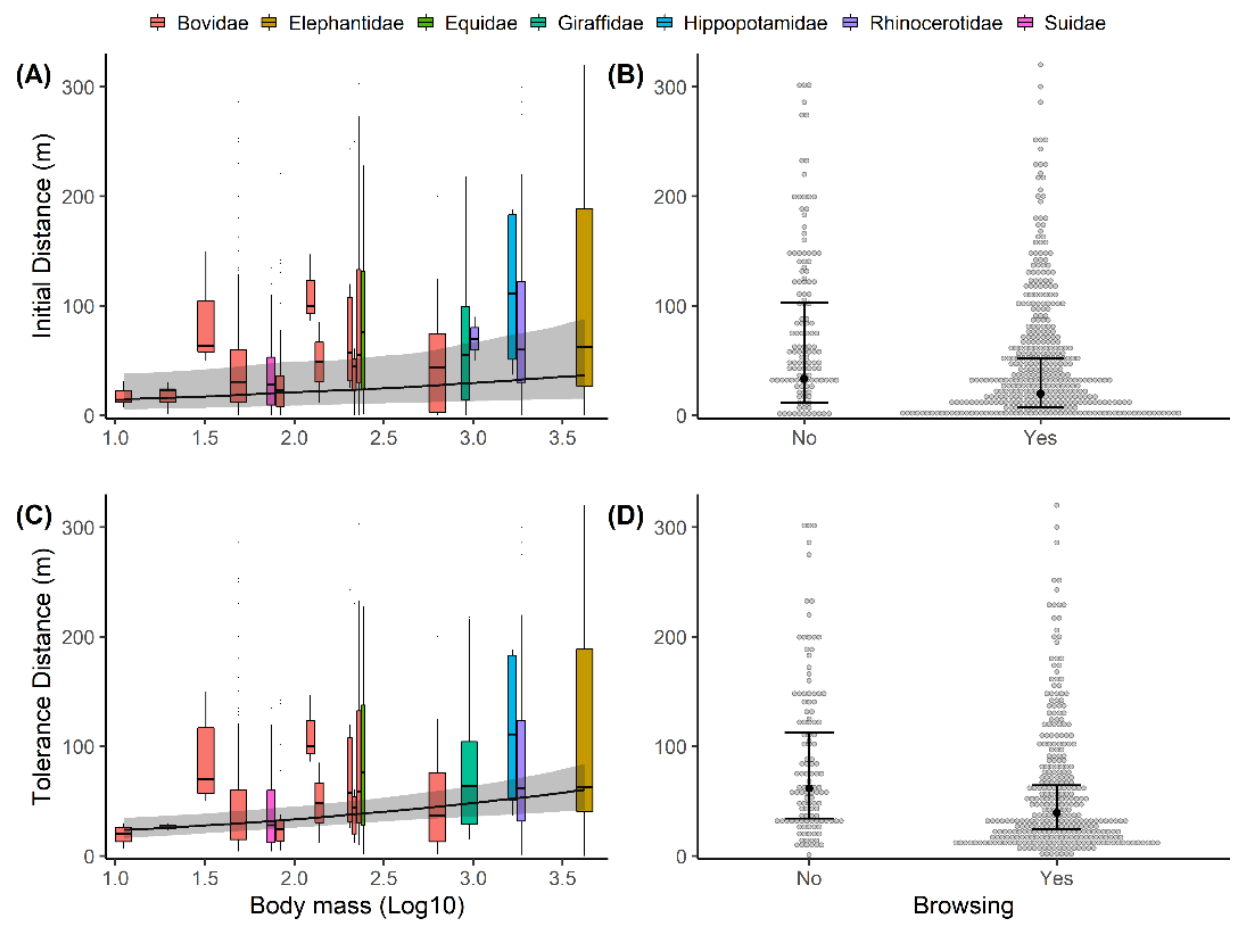

215 Figure 2. Observed (boxplots and dotplots) and predicted (line and error bars) initial (panels

$216 \mathrm{~A}$ and $\mathrm{B}$ ) and tolerance distances (C and $\mathrm{D})$ for ungulate species with different body mass

217 values and different browsing foraging habits. In panels A and C boxplots represents

218 distances observed for individual species with colours indicating the taxonomic family. 
219 Predicted values were obtained using bootstrapped predictions from fitted models (Table 3)

220 for a dataset representing the entire range of observed body mass values (for A and C), and a 221 dataset representing each category of browsing behaviour (for B and D). In both datasets all

222 other predictors set to observed mean value (predictions were made for the average

223 population, without considering random factor values). The shaded areas (in A and C) and

224 error bars (B and D) represent the 95\% confidence interval of the bootstrapped predictions.

The traits body mass and foraging habits were identified as predictors of both initial and tolerance distances. In particular, small-sized, browsing ungulates were generally found closer to roads (both for initial and tolerance distances; Fig. 2, Table 3). These results align with our methodological hypotheses, which also predict no effect for a narrower observation area within which we hypothesize detectability would be unaffected by these traits (Table 1). When we fitted models considering only observations in the first $100 \mathrm{~m}$ from each side of the road for initial distance (data for 18 species and 392 records) and for tolerance distance (17 species and 337 records) we found no effect of body mass on either distance variable (while the effects of traffic intensity and standardised group size remained the same; Supplementary materials, Table A2). Browsing species still had shorter initial and tolerance distances within $100 \mathrm{~m}$ of roads, which may reflect a different biological mechanism affecting browsing behaviour near roads. Longevity and reproductive traits (i.e. sexual maturity age, gestation length, and litters per year) were not identified as relevant predictors of initial or tolerance 239 distance.

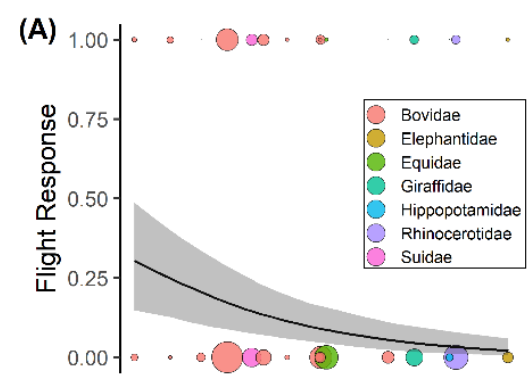

Body mass $(\log 10)$
(B)

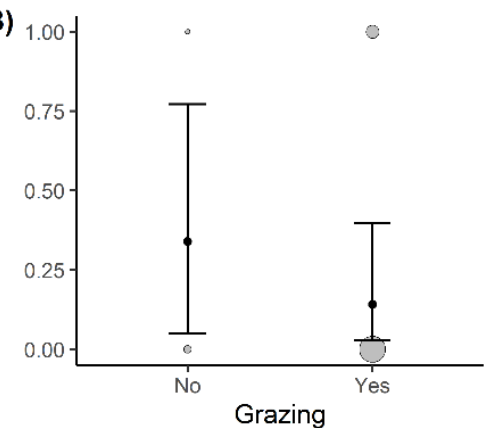

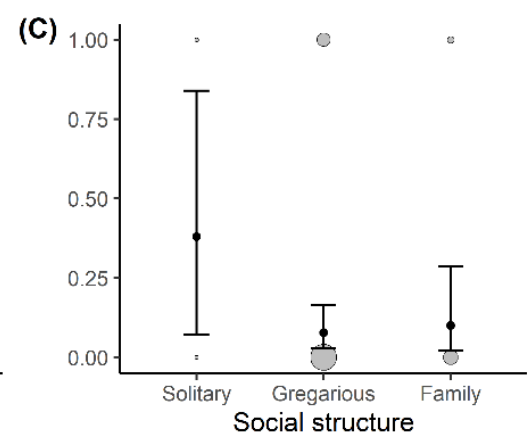

242 Figure 3. Observed (circles) and predicted (lines and error bars) flight responses for ungulate species with different body mass (A), grazing food habits (B), and social structure (C).

244 Observed values for panel A are represented grouping responses for each species, with circle 245 size proportional to the number of observations. Colours indicate the taxonomic family. 246 Predicted values were obtained for each plot using bootstrapped predictions for datasets 
representing the entire range of body mass values for A, all grazing categories for B, and all social structure categories for C. All other predictors set to observed mean value (predictions were made for the average population, without considering random factor values). The shaded area (A) and error bars (B and C) represent the 95\% confidence interval of the bootstrapped predictions.

Body mass, social aggregation and foraging habits were identified as predictors of flight responses (Fig. 3). Species with smaller body mass, solitary behaviour and non-grazing habits were more likely to flee (controlling for the significant effect of their initial distance to the road; Table 3). Longevity and reproductive traits (i.e. sexual maturity age, gestation length, and litters per year) were not identified as relevant predictors of flight responses.

Among the tested control predictors, we found a consistent effect of traffic intensity for both initial and tolerance distance, with ungulates located further from roads with more traffic, but no effect of road surface (Table 3). The standardised group size was also always important to explain initial distance, with relatively larger groups for each species often found closer to roads initially. This could reflect increased detectability when more individuals are together (larger relative group sizes). Initial distance was a strong predictor of flight responses, with ungulates located closer to roads being more likely to flee (Table 3). Collinearity among predictors was not a concern in our analyses with VIF values $<2$ in all fitted models.

\section{Discussion}

Our study is the first, to our knowledge, to test the value of species' trait models to explain and predict avoidance responses towards roads and traffic, offering a new approach to understand the mechanisms underlying the effects of infrastructures on wildlife. In particular, our results show the potential to use species traits as (biological) predictors of flight responses. We found that larger, gregarious species with grazing foraging habits are less likely to flee from vehicles.

Smaller species, such as duikers, are more susceptible to predation risk than larger species, such as rhinoceros; and thus, are expected to use anti-predatory responses, like flight responses, more often than larger species (Berger and Cunningham, 1988; Périquet et al., 2012). Indeed, our analyses show flight responses can be explained by species' body mass. Differences in risk perception may explain why we found grazing habits were associated with fewer flight responses (Valeix et al. 2009). Grazing often occurs in open habitats (PérezBarbería et al., 2001), where anti-predator vigilance is easier to perform compared to 
environments with dense vegetation within which browsing is more common and predation alertness may be higher (Caro et al., 2004). Anecdotally, we found limited flight responses (7 out of 65) in white rhinoceros Ceratotherium simum, which predominantly graze, while both observed black rhinoceros Diceros bicornis, which are browsers, flew in response to the vehicle. Finally, our results support the biological prediction that solitary species would display more frequent flight responses than gregarious species or those in family groups. Species living in groups can perform cooperative vigilance, that generally reduces individual vigilance time, but could increase the cost of false responses as the whole group, not just one individual, moves. This may lead to more accurate anti-predatory behaviours in gregarious species as they have adapted or learned to react only to real threats. Flight responses may also be rarer in groups due to a dilution effect: the individual risk of attack is lower in larger groups, but the costs of fleeing do not change (individuals still need to stop their activity, e.g., foraging, to flee); therefore, unique individual may be less likely to flee when in a larger group (Hunter and Skinner, 1998; Creel et al., 2014; Moll et al., 2016).

While our findings support biologically relevant links between species' traits and flight responses, analyses of initial and tolerance distance only supported methodological hypotheses associated with detectability. Results suggest smaller animals were closer to roads, but this relationship likely reflected lower detectability of smaller individuals at greater distances from roads (Pollock and Kendall, 1987) as no difference was detected within a 100meter range of the road. Previous studies have reported road avoidance in different ungulate species, with animals preferring areas further from roads (Mulero-Pázmány et al 2016; D'Amico et al 2016). An intriguing hypothesis derived from our results is that the roadavoidance zone is similar among species, reflecting a common boundary that is not affected by anti-predatory responses but instead may be driven by other factors (food availability, pollution effects, etc). In addition, we found browsing species closer to roads even within a 100-meter range of the road for both initial and tolerance distance. Vegetation changes, including greater local diversity, can occur near roads potentially attracting browsers to their proximity (Rea, 2003). Road avoidance by competitors or predators could also increase attractiveness of areas near roads for some species (Berger, 2007). Future studies are needed to determine if vegetation changes and/or species interactions are indeed affecting the use of areas near roads by browsing species.

While not the main focus of our study, our analyses also included some confounding variables that offer interesting insights. We found a consistent role of traffic but not of pavement surface in initial and tolerance distances. The impact of traffic on ungulate spatial 
distribution has been shown in previous studies (Leblond et al., 2013; D’Amico et al., 2016;

316 Mulero-Pázmány et al., 2016). However, because unpaved roads often have lower traffic than paved roads (Jaeger et al., 2005), previous studies could not disentangle the role of those factors. Our study was conducted in different protected areas with varying numbers of visitors which allowed us to consider both aspects jointly in our analyses without collinearity issues. The results suggest road avoidance in the studied species is influenced by traffic but not by the presence of pavement. To our knowledge this is the first time this distinction has been made, with potential implications for the management of traffic and roads in protected areas. Moreover, while flight responses were not directly affected by traffic intensity (or road surface), they were affected by initial distance, which in turn was affected by traffic, suggesting a potential indirect effect.

Overall, our study shows the potential to use trait-based models to assess road impacts, in particular, vehicle avoidance leading to flight responses. We found that several species' traits (i.e. body mass, social aggregation and foraging habits) that can potentially be used as predictors for flight responses by African ungulates. Predictive trait-based models that characterize wildlife responses to human impacts, such as roads and traffic, can be valuable tools for conservation. These models can assess risks across species and/or areas, and identify generalized risk factors that may offer insight into mitigation strategies of value for diverse species (i.e., focused on those common risk factors). In addition, predictive models can also be used to generate risk assessments for unstudied species which can be helpful for conservation and road planning. For example, we can identify areas with many susceptible species and thus, where development of new roads or additional traffic could be particularly detrimental (González-Suárez et al 2018). Future studies will be needed to establish the general value of trait-based predictive models for other regions and species. To generate those models, behavioural data from multiple sites would be very valuable. Efforts to compile larger datasets of other road impacts, such as roadkill, have already started (see González-Suárez et al., 2018). We need to expand those efforts to start collecting and compiling information on behavioural impacts to fully understand how the rapidly expanding global road-network affects wildlife, and offer tools and assessment that can aid road planning and management within protected areas and beyond.

\section{Acknowledgements}

347 Geoff Clinning, Wendy Collinson, Steve Dell, Dave Druce, Marcos Moleon, Francisco 348 Moreira, Mpho Ellen Sekgarametso, and Bob Smith provided logistic support and access to 
GIS information on the study sites. The School of Biological Sciences at the University of

350

351

352

353

354

355

356

357

358

359

360

361

362

363

364

365

366

367

368

369

370

371

372

373

374

375

376

377

378

379

380

381

Reading provided start-up funds to MGS that supported the data collection for this study. MD was funded by REN Biodiversity Chair (BPD-RENECOL), JdC-Formación (FJCI-201629182) and FCT (CEECIND/03798/2017) postdocs.

\section{References}

Animaldiversity.org (2018). ADW: Home. [online] Available at:

https://animaldiversity.org/.

Barthelmess, E. L. and Brooks, M. S. (2010). The influence of body-size and diet on road-kill trends in mammals. Biodiversity and Conservation, 19(6), 1611-1629.

Bates, D., Mächler, M., Bolker, B. and Walker, S. (2015). Fitting Linear Mixed-Effects Models Using lme4. Journal of Statistical Software, 67(1), 1-48. Available at: https://CRAN.Rproject.org/package=lme4.

Berger, J. (2007). Fear, human shields and the redistribution of prey and predators in protected areas. Biology Letters, 3, 620-623.

Berger, J. and Cunningham, C. (1988). Size-related effects on search times in North American grassland female ungulates. Ecology, 69, 177-183.

Brehme, C., Tracey, J., Mcclenaghan, L. and Fisher, R. (2013). Permeability of Roads to Movement of Scrubland Lizards and Small Mammals. Conservation Biology, 27(4), 710720.

Caro, T. M., C. M. Graham, C. J. Stoner \& J. K. Vargas (2004) Adaptive significance of antipredator behaviour in artiodactyls. Animal Behaviour, 67, 205-228.

Ceia-Hasse, A., Navarro, L. M., Borda-de-Água, L. and Pereira, H. M. (2018). Population persistence in landscapes fragmented by roads: disentangling isolation, mortality, and the effect of dispersal. Ecological Modelling, 375, 45-53.

Chen, H. L. and Koprowski, J. L. (2016). Barrier effects of roads on an endangered forest obligate: influences of traffic, road edges, and gaps. Biological Conservation, 199, 3340.

Coelho, I. P., Kindel, A. and Coelho, A. V. P. (2008). Roadkills of vertebrate species on two highways through the Atlantic Forest Biosphere Reserve, southern Brazil. European Journal of Wildlife Research, 54(4), 689-699.

Cook, T. C. and Blumstein, D. T. (2013). The omnivore's dilemma: diet explains variation in vulnerability to vehicle collision mortality. Biological Conservation, 167, 310-315. Coverdale, T. C., Kartzinel, T. R., Grabowski, K. L., Shriver, R. K., Hassan, A. A., 
Goheen, J. R., Palmer, T. M. and Pringle, R. M. (2016). Elephants in the understory: opposing direct and indirect effects of consumption and ecosystem engineering by megaherbivores. Ecology, 97, 3219-3230.

Creel, S., Schuette, P. and Christianson, D. (2014). Effects of predation risk on group size, vigilance, and foraging behavior in an African ungulate community. Behavioral Ecology, $25,773-784$.

D'Amico, M., Román, J., de los Reyes, L. and Revilla, E. (2015). Vertebrate road-kill patterns in Mediterranean habitats: who, when and where. Biological Conservation, 191, 234242.

D'Amico, M., Périquet, S., Román, J. and Revilla, E. (2016). Road avoidance responses determine the impact of heterogeneous road networks at a regional scale. Journal of Applied Ecology, 53(1), 181-190.

Eigenbrod, F., Hecnar, S. J. and Fahrig, L. (2008). Accessible habitat: an improved measure of the effects of habitat loss and roads on wildlife populations. Landscape Ecology, 23(2), 159-168.

Estes, R. (1991). The Behavior Guide to African Mammals: Including Hoofed Mammals, Carnivores, Primates. University of California Press.

Fahrig, L. and Rytwinski, T. (2009). Effects of roads on animal abundance: an empirical review and synthesis. Ecology and Society, 14(1), 21.

Ford, A. T. and Fahrig, L. (2007). Diet and body size of North American mammal road mortalities. Transportation Research Part D: Transport and Environment, 12(7), 498-505.

Forman, R. T. T. (2000). Estimate of the area affected ecologically by the road system in the United States. Conservation Biology, 14(1), 31-35.

Forman, R. and Deblinger, R. (2000). The Ecological Road-Effect Zone of a Massachusetts (U.S.A.) Suburban Highway. Conservation Biology, 14(1), 36-46.

Francis, C. D. (2015). Vocal traits and diet explain avian sensitivities to anthropogenic noise. Global Change Biology, 21(5), 1809-1820.

Francis, M. J., Spooner, P. G. and Matthews, A. (2015). The influence of urban encroachment on squirrel gliders (Petaurus norfolcensis): effects of road density, light and noise pollution. Wildlife Research, 42(4), 324-333.

Frid, A. and Dill, L. (2002). Human-caused disturbance stimuli as a form of predation risk. Conservation Ecology, 6,Fritz, S. A., Bininda-Emonds, O. R. P. and Purvis, A. (2009). Geographical variation in predictors of mammalian extinction risk: big is bad, but only in the tropics. Ecology Letters, 12, 538-549. 
Garriga, N., Santos, X., Montori, A., Richter-Boix, A., Franch, M. and Llorente, G. (2012). Are protected areas truly protected? The impact of road traffic on vertebrate fauna. Biodiversity and Conservation, 21(11), 2761-2774.

Gavin, S. D. and Komers, P. E. (2006). Do pronghorn (Antilocapra americana) perceive roads as a predation risk? Canadian Journal of Zoology, 84, 1775-1780.

González-Suárez, M., D'Amico, M. and Mulero-Pázmány, M. (2017). Advancing road ecology in Africa with robust analyses and cautious inferences: a response to Jackson et al. (2017). Journal of Zoology, 302(4), 224-227.

González-Suárez, M., Zanchetta Ferreira, F. and Grilo, C. (2018). Spatial and species427 level predictions of road mortality risk using trait data. Global Ecology and Biogeography, 27(9), 1093-1105.

Gonzalez-Voyer, A; González-Suárez, M; Vilà, C; Revilla, E (2016) Large brain size indirectly increases vulnerability to extinction in mammals. Evolution 70: 1364-1375

Grilo, C., Sousa, J., Ascensão, F., Matos, H., Leitão, I., Pinheiro, P., Costa, M., Bernardo, J., Reto, D., Lourenço, R., Santos-Reis, M. and Revilla, E. (2012). Individual spatial responses towards roads: implications for mortality risk. PLOS ONE, 7(9), p.e43811.

Hunter, L. T. B. and Skinner, J. D. (1998). Vigilance behaviour in African ungulates: the role of predation pressure. Behaviour, 135, 195-211.

Ibisch, P. L., Hoffmann, M. T., Kreft, S., Pe'er, G., Kati, V., Biber-Freudenberger, L., DellaSala, D. A., Vale, M. M., Hobson, P. R. and Selva, N. (2016). A global map of roadless areas and their conservation status. Science, 354(6318), 1423-1427.

Jachowski, D. S., Slotow, R. and Millspaugh, J. J. (2012). Physiological stress and refuge behavior by African elephants. PLoS ONE, 7(2), e31818.

Jaeger, J., Bowman, J., Brennan, J., Fahrig, L., Bert, D., Bouchard, J., Charbonneau, N., Frank, K., Gruber, B. and von Toschanowitz, K. (2005). Predicting when animal populations are at risk from roads: an interactive model of road avoidance behavior. Ecological Modelling, 185(2-4), 329-348.

Jones, K., Bielby, J., Cardillo, M., Fritz, S., O'Dell, J., Orme, C., Safi, K., Sechrest, W., Boakes, E., Carbone, C., Connolly, C., Cutts, M., Foster, J., Grenyer, R., Habib, M., Plaster, C., Price, S., Rigby, E., Rist, J., Teacher, A., Bininda-Emonds, O., Gittleman, J., Mace, G. and Purvis, A. (2009). PanTHERIA: a species-level database of life history, ecology, and geography of extant and recently extinct mammals. Ecology, 90(9), 2648-2648. on movement patterns of understory rainforest birds in central Amazonia. Conservation 
Biology, 18(4), 1099-1109.

Laurance, W., Clements, G., Sloan, S., O’Connell, C., Mueller, N., Goosem, M., Venter, O., Edwards, D., Phalan, B., Balmford, A., van Der Ree, R. and Arrea, I. (2014). A global strategy for road building. Nature, 513(7517), 229-232.

Leblond, M., Dussault, C. and Ouellet, J. P (2013). Avoidance of roads by large herbivores and its relation to disturbance intensity. Journal of Zoology, 289, 32-40.

Lian, X., Zhang, T., Cao, Y., Su, J. and Thirgood, S. (2011). Road proximity and traffic flow perceived as potential predation risks: evidence from the Tibetan antelope in the Kekexili National Nature Reserve, China. Wildlife Research, 38, 141-146.

Lima, S. L., B. F. Blackwell, T. L. DeVault \& E. Fernández-Juricic (2015). Animal reactions to oncoming vehicles: a conceptual review. Biological Reviews, 90, 60-76.

McClure, C., Ware, H., Carlisle, J., Kaltenecker, G. and Barber, J. (2013). An experimental investigation into the effects of traffic noise on distributions of birds: avoiding the phantom road. Proceedings of the Royal Society B: Biological Sciences, 280(1773), 2290-2290.

McGregor, R., Bender, D. and Fahrig, L. (2008). Do small mammals avoid roads because of the traffic? Journal of Applied Ecology, 45(1), 117-123.

Moll, R. J., Killion, A. K., Montgomery, R. A., Tambling, C. J. and Hayward, M. W. (2016). Spatial patterns of African ungulate aggregation reveal complex but limited risk effects from reintroduced carnivores. Ecology, 97, 1123-1134.

Monz, C., D'Antonio, A., Lawson, S., Barber, J. and Newman, P. (2016). The ecological implications of visitor transportation in parks and protected areas: examples from research in US National Parks. Journal of Transport Geography, 51, 27-35.

Mulero-Pázmány, M., D'Amico, M. and González-Suárez, M. (2016). Ungulate behavioral responses to the heterogeneous road-network of a touristic protected area in Africa. Journal of Zoology, 298(4), 233-240.

Ndibalema, V. G., Mduma, S., Stokke, S. and Røskaft, E. (2008). Relationship between road dust and ungulate density in Serengeti National Park, Tanzania. African Journal of Ecology, 46(4), 547-555.

Orme, D., Freckleton, R., Thomas, G., Petzoldt, T., Fritz, S., Isaac, N. and Pearse, W. (2013). caper: Comparative Analyses of Phylogenetics and Evolution in R. R package version 0.5.2. https://CRAN.R-project.org/package=caper.

Pérez-Barbería, F. J., I. J. Gordon \& C. Nores (2001) Evolutionary transitions among feeding styles and habitats in ungulates. Evolutionary Ecology Research, 3, 221-230.

Périquet, S., Todd-Jones, L., Valeix, M., Stapelkamp, B., Elliot, N., Wijers, M., Pays, 
O., Fortin, D., Madzikanda, H. and Fritz, H. (2012). Influence of immediate predation risk by lions on the vigilance of prey of different body size. Behavioral Ecology, 23, 970-976.

Pollock, K. H. and Kendall, W. L. (1987). Visibility bias in aerial surveys: a review of estimation procedures. Journal of Wildlife Management, 51, 502-510.

Pringle, R. M., Young, T. P., Rubenstein, D. I. and McCauley, D. J. (2007). Herbivoreinitiated interaction cascades and their modulation by productivity in an African savanna. Proceedings of the National Academy of Sciences, 104, 193-197.

Promislow, D.E. and Harvey, P.H. (1990). Living fast and dying young: A comparative analysis of life-history variation among mammals. Journal of Zoology, 220(3), 417-437.

R Core Team (2016). R: A Language and Environment for Statistical Computing. Vienna, Austria: R Foundation for Statistical Computing. Available at: https://www.Rproject.org.

Rea, R. V. (2003). Modifying roadside vegetation management practices to reduce vehicular collisions with moose Alces alces. Wildlife Biology, 9, 81-91.

Rytwinski, T. and Fahrig, L. (2011). Reproductive rate and body size predict road impacts on mammal abundance. Ecological Applications, 21(2), 589-600.

Rytwinski, T. and Fahrig, L. (2012). Do species life history traits explain population responses to roads? A meta-analysis. Biological Conservation, 147(1), 87-98.

Rytwinski, T. and Fahrig, L. (2013). Why are some animal populations unaffected or positively affected by roads? Oecologia, 173(3), 1143-1156.

Santos, S. M., Mira, A., Salgueiro, P. A., Costa, P., Medinas, D. and Beja, P. (2016). Avian trait-mediated vulnerability to road traffic collisions. Biological Conservation, 200, 122130.

Shultz, S. and Dunbar, R. I. M. (2006). Both social and ecological factors predict ungulate brain size. Proceedings of the Royal Society B: Biological Sciences, 273, 207-215.

Stankowich, T. (2008). Ungulate flight responses to human disturbance: a review and meta-analysis. Biological Conservation, 141(9), 2159-2173.

Street, S.E., Navarrete, A.F., Reader, A.M. and Laland, K.N. (2017). Coevolution of cultural intelligence, extended life history, sociality, and brain size in primates. Proceedings of the National Academy of Sciences, 114, 7908-7914.

Stuart, C. and Stuart, M. (2015). Stuarts' Field Guide to mammals of southern Africa. Cape Town: Penguin Random House South Africa.

Tacutu, R., Thornton, D., Johnson, E., Budovsky, A., Barardo, D., Craig, T., Diana, E., Lehmann, G., Toren, D., Wang, J., Fraifeld, V. E. and de Magalhaes, J. P. (2018). Human 
519 Ageing Genomic Resources: new and updated databases. Nucleic Acids Research, 46(D1), 520 D1083-D1090.

521 Valeix, M., Loveridge, A.J., Chamaillé-Jammes, S., Davidson, Z., Murindagomo, F., 522 Fritz, H. and Macdonald, D.W. (2009). Behavioral adjustments of African herbivores to 523 predation risk by lions: Spatiotemporal variations influence habitat use. Ecology, 90(1), 23-30. 524 Waldram, M. S., Bond, W. J. and Stock, W. D. (2008). Ecological engineering by a 525 mega-grazer: white rhino impacts on a South African savanna. Ecosystems, 11, 101-112. 
Table 1. Definition, hypothesis, predictions, and data sources of the species' traits tested as predictors of ungulate responses to roads and traffic.

\begin{tabular}{|c|c|c|c|}
\hline Group & Variable definition & Hypotheses and predictions & Source \\
\hline Morphology & $\begin{array}{l}\text { Brain mass: Average adult } \\
\text { brain mass in grams.* }\end{array}$ & $\begin{array}{l}\text { Biological: Smaller species will avoid roads/vehicles and } \\
\text { exhibit more flight responses than larger species, because } \\
\text { they have higher predation risk and thus, are more aware } \\
\text { of potential predators. } \\
\text { Methodological: Smaller species will be better detected } \\
\text { close to roads/vehicles, due to detectability decreasing } \\
\text { differently for different-sized individuals according to } \\
\text { distance. Closer to roads (e.g., <100 m) detectability } \\
\text { effects based on size should be minimized and distance to } \\
\text { road should not vary with body mass. } \\
\text { Biological: Small-brain species will avoid roads/vehicles } \\
\text { and exhibit more flight responses than large-brain species, } \\
\text { because they lack the cognitive capacities to learn that } \\
\text { road/vehicles are not as threatening as actual predators. } \\
\text { Methodological: None. }\end{array}$ & $\begin{array}{l}\text { Animaldiversity.org, 2018; } \\
\text { Estes, 1991; Jones et al., 2009; } \\
\text { Stuart and Stuart, 2015; } \\
\text { Gonzalez-Voyer } \text { et al., 2016; } \\
\text { Shultz and Dunbar, } 2006\end{array}$ \\
\hline Lifespan & $\begin{array}{l}\text { Longevity: Average lifespan in } \\
\text { years, when available in the } \\
\text { wild, and when not in } \\
\text { captivity. }\end{array}$ & $\begin{array}{l}\text { Biological: Short-lived species will avoid roads/vehicles } \\
\text { and exhibit more flight responses than long-lived species, } \\
\text { because they have a shorter experience with roads and } \\
\text { vehicles and cannot learn they are not as threatening as }\end{array}$ & $\begin{array}{l}\text { Animaldiversity.org, 2018; } \\
\text { Jones et al., 2009; Stuart and } \\
\text { Stuart, } 2015\end{array}$ \\
\hline
\end{tabular}


actual predators.

\section{Reproduction Gestation length: Average} length of gestation in years.

Litters per year: Average number of litters per year.

\section{Sexual maturity age: Sex}

specific and combined average age of sexual maturity in years.

\section{Foraging}

\section{Sociality}

Foraging habits classified as grazing (binary descriptor of whether a species grazes to feed), browsing (binary descriptor of whether a species browses to feed), or other habits (binary descriptor of whether a species consumes items other than grass and leaves).

Social aggregation classified as: solitary, gregarious, or

\section{Methodological: None.}

Biological: Slow-reproducing species will avoid

Animaldiversity.org, 2018; roads/vehicles and exhibit more flight responses than fastreproducing species, due to higher investment in self-

Estes, 1991; Jones et al., 2009, maintenance.

\section{Methodological: None.}

Biological: Browsing species will avoid roads/vehicles and exhibit more flight responses than grazing species, because they have higher predation risk and thus, are more aware of potential predators.

Methodological: Browsing species will be more detected close to roads/vehicles than far from them, due to detectability decreasing in their preferred habitat (i.e. dense vegetation). Note: closer to roads (e.g., <100 m) detectability effects should be minimized and distance to road should not vary with foraging habits.

Biological: Solitary species will avoid roads/vehicles and exhibit more flight responses than gregarious species,
Estes, 1991; Stuart and Stuart, 2015

Animaldiversity.org, 2018;

Estes, 1991; Stuart and Stuart, 
family groups.

because the lack of cooperative vigilance increases

predation risk.

Methodological: Solitary species will be more detected

close to roads/vehicles than far from them, due to

detectability decreasing according to distance. Note:

closer to roads (e.g., <100 m) detectability effects should

be minimized and distance to road should not vary with

sociality aggregation.

* For Brain Mass of Phacochoerus africanus we use data from a closely related species Phacochoerus aethiopicus. 
529 Table 2. Number of sightings of each detected species (total and within each protected area).

\begin{tabular}{lrrrr}
\hline Species & HiP & uMkhuze & Pilanesberg & Total \\
\hline Impala (Aepyceros melampus) & 74 & 16 & 54 & 144 \\
\hline White Rhino (Ceratotherium simum) & 55 & 0 & 10 & 65 \\
\hline Blue Wildebeest (Connochaetes taurinus) & 9 & 1 & 47 & 57 \\
\hline Plains Zebra (Equus quagga) & 26 & 0 & 30 & 56 \\
\hline Warthog (Phacochoerus africanus) & 37 & 0 & 10 & 47 \\
\hline Giraffe (Giraffa camelopardalis) & 17 & 2 & 16 & 35 \\
\hline Nyala (Tragelaphus angasii) & 24 & 11 & 0 & 35 \\
\hline African Buffalo (Syncerus caffer) & 14 & 0 & 0 & 14 \\
\hline African Bush Elephant (Loxodonta africana) & 5 & 0 & 7 & 12 \\
\hline Greater Kudu (Tragelaphus strepsiceros) & 4 & 1 & 7 & 12 \\
\hline Springbok (Antidorcas marsupialis) & 0 & 0 & 7 & 7 \\
\hline Steenbok (Raphicerus campestris) & 0 & 0 & 6 & 6 \\
\hline Waterbuck (Kobus ellipsiprymnus) & 1 & 0 & 5 & 6 \\
\hline Common Hippo (Hippopotamus amphibius) & 0 & 0 & 5 & 5 \\
\hline Grey Duiker (Sylvicapra grimmia) & 3 & 2 & 0 & 5 \\
\hline Tsessebe (Damaliscus lunatus) & 0 & 0 & 3 & 3 \\
\hline African Black Rhino (Diceros bicornis) & 1 & 0 & 1 & 2 \\
\hline Hartebeest (Alcelaphus buselaphus) & 0 & 0 & 211 & 513 \\
\hline Total & 270 & 34 & & 2 \\
\hline
\end{tabular}


Table 3. Coefficient estimates for models testing the effect of different traits in observed distances and flight responses. We report the best estimate $(\beta)$ with their $95 \%$ confidence intervals, and the number of observations $(\mathrm{N})$. All models included road surface, traffic intensity, and standardized group size as control predictors; the model for flight response also included initial distance as a control predictor. For several traits we used standardized residuals from a phylogenetic least squares models in which the $\log _{10}$-transformed trait was predicted by $\log _{10}($ body mass $)$ with taxonomic order as a covariate to avoid the potential confounding effect of size. Predictors with 95\%CI (bootstrapped estimates) nonoverlapping with zero are marked in bold. We did not record tolerance distance for black rhino Diceros bicornis.

\begin{tabular}{|c|c|c|c|c|c|c|}
\hline \multirow[t]{2}{*}{ Models } & \multicolumn{2}{|c|}{$\begin{array}{c}\text { Initial distance } \\
(\mathrm{N}=513,18 \text { species })\end{array}$} & \multicolumn{2}{|c|}{$\begin{array}{l}\text { Tolerance distance } \\
(\mathrm{N}=448,17 \text { species) }\end{array}$} & \multicolumn{2}{|c|}{$\begin{array}{c}\text { Flight response } \\
(\mathrm{N}=513,18 \text { species })\end{array}$} \\
\hline & $\beta$ & $95 \% \mathrm{CI}$ & $\beta$ & $95 \% \mathrm{CI}$ & $\beta$ & $95 \% \mathrm{CI}$ \\
\hline \multicolumn{7}{|l|}{ Lifespan } \\
\hline Intercept & 1.549 & $1.083-1.764$ & 1.648 & $1.524-1.770$ & -1.998 & $-3.058--1.202$ \\
\hline Road surface (unpaved) & -0.042 & $-0.166-0.140$ & 0.034 & $-0.084-0.146$ & -0.198 & $-0.992-0.620$ \\
\hline Traffic intensity & 0.112 & $0.038-0.196$ & 0.091 & $0.033-0.148$ & -0.338 & $-1.027-0.082$ \\
\hline Standardized group size & -0.058 & $-0.109--0.009$ & -0.016 & $-0.054-0.020$ & -0.067 & $-0.372-0.211$ \\
\hline Initial distance $\left(\log _{10}\right)$ & - & - & - & - & -1.344 & $-1.742--1.046$ \\
\hline Longevity (residuals) & 0.042 & $0.003-0.149$ & 0.022 & $-0.044-0.085$ & 0.246 & $-0.306-0.760$ \\
\hline \multicolumn{7}{|l|}{ Morphology } \\
\hline Intercept & 1.397 & $1.050-1.748$ & 1.615 & $1.507-1.726$ & -1.954 & $-2.728--1.430$ \\
\hline Road surface (unpaved) & 0.000 & $-0.169-0.161$ & 0.048 & $-0.069-0.159$ & -0.060 & $-0.787-0.715$ \\
\hline Traffic intensity & 0.121 & $0.041-0.202$ & 0.096 & $0.036-0.154$ & -0.304 & $-0.950-0.098$ \\
\hline
\end{tabular}




\begin{tabular}{|c|c|c|c|c|c|c|}
\hline Standardized group size & -0.058 & $-0.109--0.004$ & -0.016 & $-0.055-0.021$ & -0.077 & $-0.405-0.193$ \\
\hline Initial distance $\left(\log _{10}\right)$ & - & - & - & - & -1.283 & $-1.638--1.024$ \\
\hline Body mass $\left(\log _{10}\right)$ & 0.090 & $0.029-0.221$ & 0.095 & $0.036-0.154$ & -0.600 & $-0.973--0.303$ \\
\hline Brain mass (residuals) & 0.025 & $-0.039-0.154$ & 0.012 & $-0.042-0.063$ & -0.223 & $-0.611-0.132$ \\
\hline \multicolumn{7}{|l|}{ Reproductive speed } \\
\hline Intercept & 1.437 & $1.076-1.805$ & 1.650 & $1.526-1.776$ & -2.005 & $-3.099--1.197$ \\
\hline Road surface (unpaved) & -0.011 & $-0.183-0.148$ & 0.038 & $-0.074-0.149$ & -0.189 & $-0.947-0.599$ \\
\hline Traffic intensity & 0.118 & $0.040-0.198$ & 0.092 & $0.035-0.147$ & -0.321 & $-1.070-0.086$ \\
\hline Standardized group size & -0.057 & $-0.109--0.004$ & -0.016 & $-0.052-0.022$ & -0.066 & $-0.395-0.214$ \\
\hline Initial distance $\left(\log _{10}\right)$ & - & - & - & - & -1.344 & $-1.732--1.043$ \\
\hline Sexual maturity age (residuals) & -0.069 & $-0.101-0.094$ & -0.056 & $-0.119-0.011$ & 0.317 & $-0.259-0.928$ \\
\hline Gestation length (residuals) & -0.009 & $-0.178-0.098$ & 0.011 & $-0.072-0.090$ & -0.219 & $-0.954-0.560$ \\
\hline Litters per year (residuals) & -0.061 & $-0.121-0.096$ & -0.041 & $-0.111-0.031$ & -0.307 & $-0.947-0.396$ \\
\hline \multicolumn{7}{|l|}{ Foraging } \\
\hline Intercept & 1.612 & $1.152-2.088$ & 1.923 & $1.651-2.196$ & 0.398 & $-2.228-3.082$ \\
\hline Road surface (unpaved) & -0.021 & $-0.182-0.144$ & 0.034 & $-0.084-0.146$ & -0.177 & $-1.035-0.692$ \\
\hline Traffic intensity & 0.116 & $0.034-0.198$ & 0.092 & $0.034-0.148$ & -0.326 & $-1.116-0.143$ \\
\hline Standardized group size & -0.057 & $-0.112--0.005$ & -0.017 & $-0.053-0.020$ & -0.079 & $-0.425-0.232$ \\
\hline Initial distance $\left(\log _{10}\right)$ & - & - & - & - & -1.348 & $-1.762--1.057$ \\
\hline Grazing & -0.006 & $-0.298-0.281$ & -0.139 & $-0.362-0.089$ & -2.317 & $-4.626--0.482$ \\
\hline Browsing & -0.228 & $-0.445--0.004$ & -0.190 & $-0.355--0.028$ & -0.957 & $-2.840-1.090$ \\
\hline
\end{tabular}




\begin{tabular}{|c|c|c|c|c|c|c|}
\hline Other foods & -0.064 & $-0.317-0.191$ & -0.090 & $-0.277-0.096$ & 1.085 & $-0.786-2.945$ \\
\hline \multicolumn{7}{|l|}{ Social structure } \\
\hline Intercept & 1.394 & $1.024-1.826$ & 1.376 & $1.005-1.739$ & 0.342 & $-1.429-2.591$ \\
\hline Road surface (unpaved) & -0.037 & $-0.194-0.122$ & 0.036 & $-0.073-0.150$ & -0.170 & $-0.977-0.705$ \\
\hline Traffic intensity & 0.109 & $0.033-0.185$ & 0.089 & $0.036-0.146$ & -0.308 & $-1.093-0.128$ \\
\hline Standardized group size & -0.058 & $-0.108--0.004$ & -0.016 & $-0.052-0.021$ & -0.071 & $-0.434-0.217$ \\
\hline Initial distance $\left(\log _{10}\right)$ & - & - & - & - & -1.335 & $-1.733--1.049$ \\
\hline Social: gregarious & 0.177 & $-0.252-0.555$ & 0.295 & $-0.070-0.656$ & -2.741 & $-5.154--0.873$ \\
\hline Social: family groups & 0.131 & $-0.327-0.546$ & 0.250 & $-0.141-0.638$ & -2.443 & $-5.314--0.419$ \\
\hline
\end{tabular}


